\title{
Perioperative complications of radical retropubic prostatectomy in patients with locally advanced prostate cancer: a comparison with clinically localized prostate cancer
}

\begin{abstract}
Xu-Dong Yao ${ }^{1 *}$, Xiao-Jun Liu ${ }^{2 *}$, Shi-Lin Zhang ${ }^{1}$, Bo Dai ${ }^{1}$, Hai-Liang Zhang ${ }^{1}$ and Ding-Wei Ye ${ }^{1}$
Radical prostatectomy (RP) continues to be an effective surgical therapy for prostate carcinoma, particularly for organ-confined prostate cancer (PCa). Recently, RP has also been used in the treatment of locally advanced prostate cancer. However, little research has been performed to elucidate the perioperative complications associated with RP in patients with clinically localized or locally advanced PCa. We sought to analyse the incidence of complications in these two groups after radical retropubic prostatectomy (RRP). From June 2002 to July 2010, we reviewed 379 PCa patients who underwent RRP in our hospital. Among these cases, 196 had clinically localized PCa ( $\mathrm{T}_{1 \mathrm{a}}-\mathrm{T}_{2 \mathrm{c}}$ : group 1 ), and 183 had locally advanced $\mathrm{PCa}$ ( $\geqslant \mathrm{T}_{3 \mathrm{a}}$ : group 2 ). The overall complication incidence was $\mathbf{2 1 . 9 \%}$, which was lower than other studies have reported. Perioperative complications in patients with locally advanced PCa mirror those in patients with clinically localized $\mathrm{PCa}(26.2 \%$ vs. $17.8 \%, P=0.91)$. Our results showed that perioperative complications could not be regarded as a factor to consider in regarding $\mathrm{RP}$ in patients with $\mathrm{CT}_{3}$ or greater.
\end{abstract}

Asian Journal of Andrology (2013) 15, 241-245; doi:10.1038/aja.2012.120; published online 10 December 2012

Keywords: complications; clinically localized prostate cancer; locally advanced prostate cancer; prostate cancer (PCa); prostatectomy; radical retropubic prostatectomy $(\mathrm{RRP})$

\section{INTRODUCTION}

Through the widespread use of digital rectal exam (DRE) and prostate-specific antigen (PSA) testing, most people with prostate cancer (PCa) are diagnosed with clinically localized disease. Because of this, the incidence of locally advanced PCa has sharply decreased. ${ }^{1}$ However, treatment of locally advanced PCa is still a complex issue for patients and doctors around the world.

Various management options can be selected to treat patients with organ-confined $\mathrm{PCa}$, and radical prostatectomy (RP) has become the standard treatment for localized cancer. ${ }^{2-4}$ Nevertheless, the most effective method for locally advanced cases remains controversial. External beam radiation, hormonal therapy, or a combination of both, as well as RP, have been used to treat these patients. ${ }^{5-8}$ Xylinas et al. ${ }^{9}$ reported that radiotherapy combined with extended hormone therapy was the first choice for $\mathrm{cT}_{3}$ PCa. According to the USA National Cancer Institute's guidelines, external beam radiotherapy is the most suitable treatment for the majority of patients with advanced PCa. ${ }^{10}$ According to recent studies, however, the European Association of Urology guidelines regard $\mathrm{RP}$ as a primary therapy method in $\mathrm{cT}_{3}$ disease. ${ }^{11}$

In this context, it is urgent for us to evaluate the outcome of RP for patients with locally advanced disease. One institution implemented $\mathrm{RP}$ for patients with $\mathrm{cT}_{3}$ over a long period and concluded that $\mathrm{RP}$ can effectively control tumours in locally advanced cases. Considering the progress in this surgical technique, the complication rates have become similar to those of RP for organ-confined tumours. ${ }^{12}$ Recently, many studies have compared other aspects of these two types of cancer patients after RP, such as long-term and overall outcomes, ${ }^{12-14}$ but the degree of perioperative complication rates in these patients is largely unknown. In the present study, our goal was to compare perioperative complications in patients with clinically localized and locally advanced PCa.

\section{MATERIALS AND METHODS}

Patients

Between June 2002 and July 2010, we analysed the clinical outcomes of 379 patients who underwent radical retropubic prostatectomy (RRP) at our medical centre. Of the 379 patients, 196 (51.7\%) had clinically localized PCa, and 183 (48.3\%) had locally advanced PCa. None of these patients had used neoadjuvant therapy previously. Clinical stage was classified according to the preoperative DRE findings and was confirmed by examining patients under anaesthesia during the operation based on the 2002 Tumor Lymph Node Metastasis classification. Several comorbidities were classified according to the modified Charlson score. ${ }^{15}$ Dyslipidemia, coronary heart disease and diabetes mellitus were the most common comorbidities. The baseline characteristics of the patients are summarized in Table 1. All patients were informed of the details of this study and consented to the use of their 
medical records for this study before the analysis began. This study was approved by the internal review board (Shanghai, China).

\section{Preoperative procedures}

Before the operation, we performed a complete physical examination, measured all patients' serum PSAs, and implemented DRE and ultrasound-guided transrectal prostatic systemic biopsies. Routine blood chemistry, chest X-rays and abdominal ultrasounds were performed for all patients. One-scan abdominal and pelvic computerized tomography and magnetic resonance imaging were performed on special patients whose diagnosis was not clear with the above-mentioned examination. There was no evidence of distant metastasis. Prophylactic anticoagulant drugs and single doses of intravenous antibiotics were administered preoperatively. In addition, elastic stockings were used for all patients.

\section{Perioperative procedures}

We used the standardized surgical method published by Walsh and Donker ${ }^{16}$ with minor modifications. Two drainage tubes were regularly used to drain liquid from the pelvic cavities of all patients and were removed when secretion was less than $50 \mathrm{ml}$ within $24 \mathrm{~h}$. The urethral catheter was removed on postoperative day 10 or sooner, when urethrovesical anastomosis was shown to be sufficient on cystography. However, we prolonged the duration of bladder catheterisation in cases of severe adhesion around the prostate, severe bleeding, difficulties in urethrovesical anastomosis or sustained fluid drainage. Perioperative complications were described as any side effects appearing within 30 days of surgery. All data that were related to patients and side effects, including the amount of bleeding, the time of operation, the positive surgical margin and the complication rate, were recorded in detail. Perioperative mortality was defined as death caused by any reason within 1 month of surgery.

\section{Follow-up study}

When patients were discharged from hospital, they were asked to return to the hospital for a check-up. After RP, patients returned at 8 weeks and every 3 months thereafter for the first two years. Subsequent follow-up visits were scheduled every 6 months. During each visit, we inquired about incontinence and recorded the number

Table 1 Comparison of the basic characteristics of patients who underwent radical prostatectomy

\begin{tabular}{|c|c|c|c|}
\hline Parameters & Group 1 & Group 2 & $P$ \\
\hline Total number (\%) & $196(51.7)$ & $183(48.3)$ & \\
\hline Age (year), mean \pm s.d. & $66.6 \pm 8.6$ & $67.9 \pm 8.9$ & 0.15 \\
\hline $\begin{array}{l}\left.\text { Preoperative serum PSA (ng } \mathrm{ml}^{-1}\right) \text {, } \\
\text { mean } \pm \text { s.d. }\end{array}$ & $7.8 \pm 5.6$ & $56.7 \pm 46.9$ & $<0.001$ \\
\hline Gleason score, $n(\%)$ & & & $<0.05$ \\
\hline$\leqslant 6$ & $31(15.8)$ & $10(5.5)$ & \\
\hline 7 & $71(36.2)$ & $68(37.2)$ & \\
\hline$\geqslant 8$ & $27(13.8)$ & $72(39.3)$ & \\
\hline BMI $\left(\mathrm{kg} \mathrm{m}^{-2}\right), n(\%)$ & & & 0.08 \\
\hline$<25$ & 139 (70.9) & $115(62.8)$ & \\
\hline $25-30$ & 32 (16.3) & 35 (19.1) & \\
\hline$\geqslant 30$ & $25(12.8)$ & $33(18.0)$ & \\
\hline Charlson score, $n(\%)$ & & & 0.15 \\
\hline 0 & $103(52.6)$ & $93(50.8)$ & \\
\hline 1 & $51(26.0)$ & $60(32.8)$ & \\
\hline 2 & $32(16.3)$ & $21(11.5)$ & \\
\hline$\geqslant 3$ & $10(5.1)$ & $9(4.9)$ & \\
\hline
\end{tabular}

Abbreviations: BMI, body mass index; PSA, prostate-specific antigen. of urine pads the patients used. Serum PSA and DRE were performed routinely. We called the patients to inquire whether they had experienced any discomfort after the operation. The average follow-up duration was 30 months (range: 5-60 months).

\section{Statistical analysis}

We used the $t$-test, chi-square test and analysis of variance to compare preoperative and perioperative variables between the two groups. The data are presented as the mean \pm s.d. or as frequencies and percentages. Statistical analysis was performed using SAS software SAS 9.1.3, and $P<0.05$ was considered statistically significant.

\section{RESULTS}

\section{Patients' characteristics}

Three hundred and seventy-nine patients who underwent RRP were included in this study. The clinical and pathological characteristics of group 1 and group 2 are described in detail in Table 1. No significant difference was identified regarding mean age ( $P=0.15$; $t$-test), body mass index or Charlson score $(P=0.08, P=0.15$, respectively; chi-square test) between the two groups, but the mean values of preoperative PSA $(P<0.001 ; t$-test $)$ and biopsy Gleason scores $(P<0.05$; chi-square test) in group 1 patients were higher than those in group 2.

\section{Clinical and pathological characteristics}

Postoperative pathologically advanced disease was found in 178 patients $(46.9 \%)$. Positive surgical margins were achieved in 69 patients $(18.2 \%)$, and there was a significant difference regarding positive surgical margins between the two groups $(P<0.05$; chi-square test). Distinct from the pathological results, no differences were present regarding operation time $(P=0.22 ; t$-test $)$, estimated blood loss $(P=0.27 ; t$-test $)$, length of hospital stay $(P=0.18$; $t$-test $)$, or even catheterisation $(P=0.24 ; t$-test $)$ between groups 1 and 2 . One hundred and seventy-five $(89.3 \%)$ patients were found negative lymph node (nodal stage $\left.\mathrm{N}_{0}\right)$, the incidence of which mirrored that in group $2(87.4 \%)$. Twenty-three patients $(12.6 \%)$ reported lymph node metastasis (nodal stage $\mathrm{N}_{1}$ ) in group 2, which was greater than in group 1 (21 cases, $10.7 \%$ chi-square test), although no significant difference was found between these groups with regard to lymph node metastasis (Table 2).

\section{Perioperative complications and treatment}

Complications were graded based on the modified Clavien classification. ${ }^{17}$ The total complication incidence was approximately $21.9 \%$; group 1 occurred in $17.8 \%$ less than group $2(26.2 \%)$, although there was no statistically significant difference between these two groups $(P=0.91)$. No patient included in the study died from perioperative complications, as presented in detail in Table 3.

Lymphorrhoea was the most common complication observed for both group 1 and 2; this complication occurred in 11 and 15 patients, respectively. We treated the lymphorrhoea with continued suction drainage over a week. Major bleeding occurred in 12 patients (five in group 1 and seven in group 2) during the operation, and patients who had tachycardia or hypotension as a result of intraoperative blood loss received an allogeneic blood transfusion. No difference was found in blood loss between the two groups. Early in the use of RP, seven cases suffered rectal injuries; three of these injuries occurred in group 2. All rectal injuries were treated by cleaning the wound with iodine and performing a two-layer suture and exact vesicourethral anastomoses to achieve a single-stage repair. Ureteral injuries, the least common complication in our study, were identified in six cases during the 
Table 2 Intraoperative and perioperative variables for the two groups

\begin{tabular}{lccr}
\hline Variables & $\begin{array}{c}\text { Group 1 } \\
(\mathrm{n}=196)\end{array}$ & $\begin{array}{c}\text { Group 2 } \\
(\mathrm{n}=183)\end{array}$ & $\mathrm{P}$ \\
\hline Pathological stage, $n$ (\%) & & & $<0.05$ \\
$\quad \mathrm{pT}_{2}$ & $158(80.6)$ & $43(23.5)$ & \\
$\mathrm{pT}_{3}$ & $38(19.4)$ & $137(74.9)$ & \\
$\mathrm{pT}_{4}$ & 0 & $3(1.6)$ & \\
Operation time (min), mean \pm s.d. & $159.4 \pm 16.1$ & $161.7 \pm 20.4$ & 0.22 \\
Positive surgical margins, $n$ (\%) & $21(10.7)$ & $48(26.2)$ & $<0.05$ \\
Estimated blood loss (ml) & $674.6 \pm 143.0$ & $691.4 \pm 151.8$ & 0.27 \\
Length of stay (day) & $6.6 \pm 2.2$ & $6.9 \pm 2.3$ & 0.18 \\
Catheterisation (day) & $8.9 \pm 1.9$ & $9.1 \pm 2.2$ & 0.24 \\
Nodal stage, $n$ (\%) & & & 0.32 \\
$\quad N_{0}$ & $175(89.3)$ & $160(87.4)$ & \\
$N_{1}$ & $21(10.7)$ & $23(12.6)$ & \\
\hline
\end{tabular}

Abbreviations: $\mathrm{N}_{0}$, negative lymph node; $\mathrm{N}_{1}$, positive lymph node.

operation; equal numbers of ureteral injuries occurred in both groups. These injuries were repaired primarily with a ureteral stent, and one case (group 2) required an ureteroneocystostomy. Complications that occurred during the perioperative period were all managed properly and in a timely manner.

\section{Follow-up results}

During the follow-up, one patient (group 1) died from another disease approximately 3 years after surgery; thus, the mortality was $0.26 \%$. The PSA level decreased to $0.2 \mathrm{ng} \mathrm{ml}^{-1}$ in most patients (58\%) over an average of 2.3 weeks, and this decrease was observed in $91.2 \%$ of the cases within the first 2 years after operation. Biochemical recurrence was defined as a serum PSA value of $0.2 \mathrm{ng} \mathrm{ml}^{-1}$ that continuously increased or as a single detectable PSA value that was detected after treatment with other therapies, such as hormones or radiation. ${ }^{18}$ Postoperative PSA values greater than $0.2 \mathrm{ng} \mathrm{ml}^{-1}$ were detected in 40 cases $(10.5 \%)$; among these cases, there were 11 cases $(2.9 \%)$ and 29 cases $(7.6 \%)$ in groups 1 and 2, respectively. Two patients reported bone metastasis at 2 and 4 years after operation, and both of these patients received hormone therapy. No evidence or recurrence or metastasis was observed in $81.2 \%$ cases in the first 2 postoperative years. Urinary continence (absolutely dry or seldom moist) at the first year reached $82 \%$ in group 2 and $85 \%$ in group 1 . Severe incontinence (more than two pads a day) was rarely observed in group 2 (nine patients). After the operation, $18 \%$ and $31 \%$ patients underwent

Table 3 Perioperative complications and postoperative recurrence in radical prostatectomy

\begin{tabular}{|c|c|c|c|c|}
\hline & Total (\%) & $\begin{array}{l}\text { Group } 1 \\
(n=196)\end{array}$ & $\begin{array}{l}\text { Group } 2 \\
(n=183)\end{array}$ & $P$ \\
\hline Complication, $n(\%)$ & $83(21.9)$ & 35 (17.8) & $48(26.2)$ & 0.91 \\
\hline \multicolumn{5}{|l|}{ During surgery, $n(\%)$} \\
\hline I Ureteral injury & $6(1.6)$ & $3(1.5)$ & $3(1.6)$ & 0.93 \\
\hline I Rectal injury & $7(1.8)$ & $4(2.0)$ & $3(1.6)$ & 0.77 \\
\hline \multicolumn{5}{|l|}{ Short-term, $n(\%)$} \\
\hline $\begin{array}{l}\text { I Premature loss of } \\
\text { catheter }\end{array}$ & $10(2.6)$ & $4(2.0)$ & $6(3.3)$ & 0.45 \\
\hline I Anastomotic leakage & $13(3.4)$ & $5(2.6)$ & $8(4.4)$ & 0.33 \\
\hline II Major bleeding & $12(3.2)$ & $5(2.6)$ & $7(3.8)$ & 0.48 \\
\hline II Deep vein thrombosis & $9(2.4)$ & $3(1.5)$ & $6(3.3)$ & 0.26 \\
\hline III Lymphorrhoea & $26(6.9)$ & $11(5.6)$ & $15(8.2)$ & 0.32 \\
\hline \multicolumn{5}{|l|}{ Functional outcomes, $n(\%)$} \\
\hline Incontinence & $61(16.1)$ & 29 (14.8) & 32 (17.5) & 0.51 \\
\hline
\end{tabular}

adjuvant therapy at some point. No significant difference was found regarding the initiation of other treatments between group 1 (4.5 years) and group 2 (4.1 years).

\section{DISCUSSION}

Although a large number of studies ${ }^{19,20}$ have focused on locally advanced $\mathrm{PCa}$, the definition of this type of PCa remains ambiguous. Defining this term has been difficult for urologists and oncologists in the United Kingdom, who have not been able to reach a consensus. ${ }^{21}$ Locally advanced PCa was regarded as a clinical diagnosis indicating that the tumour extended outside the prostate capsule without any evidence of lymph node involvement or distant metastasis. This corresponds to stage $T_{3}$ in the 1992 Tumor Lymph Node Metastasis classification system of the Union International Contre le Cancer. ${ }^{22,23}$ Owing to the existing deficit of clinical data and images, this type of PCa may include the pathological $\mathrm{T}_{2}-\mathrm{T}_{4}$ stages, which can be confirmed from the histopathological specimen after surgery. ${ }^{24}$ We defined locally advanced $\mathrm{PCa}$ as cases with a $\mathrm{CT}_{3}$ or greater, regardless of the serum PSA or Gleason score after evaluating the DRE and PSA level.

Previously, radiation therapy was the preferred choice for the treatment of locally advanced PCa. However, the adverse events induced by radiation therapy are a significant concern for patients who are treated in this manner. In addition, many studies have advocated the combination of radiation and endocrine therapy as the first choice for patients with locally advanced PCa. ${ }^{8,25}$ Unfortunately, these patients were prone to node invasion and recurrence. Thus, the consensus that surgery was superior to other therapies was reached, at least to some extent. ${ }^{26}$ Recently, increasing amounts of data have shown that the gradual reduction in morbidity and complications from RP has resulted in an increased use of this surgery as an effective treatment for patients with locally advanced PCa. ${ }^{7,27,28}$ Freedland et al. ${ }^{27}$ showed that half of the locally advanced PCa patients who underwent RP achieved better long-term outcomes, leading to a specific survival rate of $84 \%$ at 15 years after the operation. RRP has been utilized in advanced cases, although the surgical benefits are still debated, especially regarding the outcomes of perioperative complications.

In our research, by examining preoperative variables and perioperative results, we made a comparison of the use of RRP for patients with locally advanced PS PCa vs. clinically localized PCa. Because of the effects of neoadjuvant hormonal therapy on the results, we excluded patients receiving hormonal therapy before operation from our analyses. Local tumour control without residual disease is the key goal for patients with locally advanced PCa. We performed extensive lymph node dissection and found that $12.6 \%$ of the cases with locally advanced PCa reported lymph node metastasis; this result was also observed in group 1 . According to different studies, the incidence of lymph node metastasis varies from $17 \%$ to $31 \%$. ${ }^{9}$ This inconsistency may be caused by the use of different methods, such as abdominopelvic scanners or fine-needle aspiration biopsies for selecting patients. The rate of positive surgical margins ranged from $15 \%$ to $35 \%$, depending on the surgeon's experience; ${ }^{11}$ in our study, this rate was $18.2 \%$, which was slightly less than that reported by Carver et al. ${ }^{7}$

Regarding perioperative morbidity, we found that the rate of complications has been greatly reduced by improvements in surgical techniques and the adoption of some precautionary measures. Blood loss has been the primary complaint since the introduction of RRP. ${ }^{29}$ By suturing the periprostatic tissue with a small-calibre, rapidly absorbed prophylactic suture line prior to the extirpation of the prostate, blood loss was significantly reduced during RRP. This finding has been confirmed by other reports. ${ }^{30}$ Löppenberg et al. ${ }^{31}$ reported that the most 
common complication in their research was anastomotic leakage, which occurred in $424(14.7 \%)$ patients. In our study, 13 (3.4\%) cases of anastomotic leakage were reported. This complication was more common in group 2 (eight cases) than in group 1 (five cases), but the difference was not significant. Before implementing the vesicourethral anastomosis, we tailored the posterior region of the bladder neck, which facilitated a water-tight anastomosis. The incidences of rectal injury $(1.8 \%)$ and ureteral injury (1.6\%) were lower in these patients, with a reported incidence of $0.5 \%-2.1 \%{ }^{32,33}$ and $0.05 \%-1.6 \%,{ }^{34,35}$ respectively. We treated patients with comorbidities in the same way as we treated patients without comorbidities, and no significant differences were found between these two groups. Overall, the total incidence of perioperative complications was $21.9 \%$, which was similar to that of another report $(23.8 \%) .{ }^{36}$ Among these patients, 35 and 48 cases occurred in groups 1 and 2, respectively. Despite the rate of group 2 being higher than that of group 1, there was no statistically significant difference between these two groups.

Few trials have studied the functional outcomes. Loeb et al. ${ }^{37}$ concluded that $96 \%$ of patients were dry, which is a satisfactory result regarding urinary continence; no difference was found between patients with $\mathrm{T}_{2}$ vs. $\mathrm{T}_{3}$ stage $\mathrm{PCa}{ }^{31}$ In a study with a total of $842 \mathrm{cT}_{3}$ patients undergoing RP, 79\% of cases were dry or used urine pads to prevent incontinence after one year of follow-up. ${ }^{12}$ Penson et al. ${ }^{38}$ reported that $14 \%$ of patients reported severe urinary leakage and that $28 \%$ of men maintained erections firm enough for intercourse 5 years after surgery in a total 1288 patients, of whom $\mathrm{pT}_{3}$ accounted for $29 \%$. In the present study, urinary continence (absolutely dry or seldom moist) at the first year of follow-up reached $82 \%$ in group 2 and $85 \%$ in group 1 . Severe incontinence (more than two pads a day) was rare in group 2, occurring in nine patients, which is in agreement with other reports. Given that erectile dysfunction is associated with aging and that the patients were almost 65 years old, we did not analyse impotence in our study.

Several studies have hypothesized that surgery alone could not achieve a complete remission and that surgery needed to be combined with adjuvant therapy or radiation. In the Mayo Clinic studies, ${ }^{12}$ most patients with $\mathrm{T}_{3}$ disease, pathological extracapsular invasion and/or seminal vesicles underwent RP alone, and adjuvant therapy was given to special cases after the operation. These studies showed that biochemical recurrence was greatly reduced by adjuvant or radiation therapy. In our study, $31 \%$ of the patients received adjuvant therapy after operation in group 2, while only $18 \%$ received adjuvant therapy in group $1(P<0.05)$. In these specific cases, adjuvant therapy was part of a multimodal treatment and provided a survival benefit.

Now, increasing numbers of surgeons intend to apply RP for locally advanced PCa with any Gleason score because Audenet et al. ${ }^{39}$ reported that there was no clear evidence to exclude $\mathrm{T}_{3}$ patients with a Gleason score of 8 or greater from surgical candidacy. ${ }^{7}$ Because of the favourable perioperative outcomes for locally advanced $\mathrm{PCa}$, the increased experience of surgeons and the technical advances in surgical instruments, this surgery has gradually expanded its applications and could be a viable initial treatment, without serious adverse events, for patients with locally advanced PCa. However, future research must continue to focus on improving the local control outcomes in patients with locally advanced cancer. There were several limitations of our study. First, this study was a retrospective design. In addition, we only reported short-term complications, as we focused on perioperative complications between these two groups over a short follow-up duration. Thus, we did not thoroughly analyse long-term outcomes, clinical disease progression or prostate cancer-specific death. Therefore, long-term follow-up is needed to assess these aspects in patients with locally advanced PCa.

\section{AUTHOR CONTRIBUTIONS}

XDY conceived of the concept and conducted critical review. XJL made great contribution on data collecting and drafting the manuscript. SLZ collected the clinical data, concentrated on following up and completed the tables. BD and HLZ were responsible for statistical analysis. DWY communicated with patients and ethics committee, and participated in drafting the article and conducted critical review. All authors read and approved the final manuscript.

\section{COMPETING FINANCIAL INTERESTS}

All authors declare that there is no conflicting financial interest.

1 Moore AL, Dimitropoulou P, Lane A, Powell PH, Greenberg DC et al. Population-based prostate-specific antigen testing in the UK leads to a stage migration of prostate cancer. BJU Int 2009; 104: 1592-8.

2 Heidenreich A, Aus G, Bolla M, Joniau S, Matveev VB et al. EAU guidelines on prostate cancer. Arnhem: European Association of Urology; 2010 [updated 2010]. http:// www.uroweb.org/guidelines/online-guidelines/

3 Ham WS, Park SY, Rha KH, Kim WT, Choi YD. Robotic radical prostatectomy for patients with locally advanced prostate cancer is feasible: results of a singleinstitution study. J Laparoendosc Adv Surg Tech A 2009; 19: 329-32.

4 Albertsen PC, Hanley JA, Penson DF, Barrows G, Fine J. 13-year outcomes following treatment for clinically localized prostate cancer in a population based cohort. J Urol 2007; 177: 932-6.

5 Stratton KL, Chang SS. Locally advanced prostate cancer: the role of surgical management. BJU Int 2009; 104: 449-54.

6 Valicenti RK. The management of locally advanced prostate cancer. Prostate Cancer Prostatic Dis 2002; 5: 8-11.

7 Carver BS, Bianco FJ, Scardino PT, Eastham JA. Long-term outcome following radical prostatectomy in men with clinical stage $T_{3}$ prostate cancer. J Urol 2006; 176: 564-8.

8 Gray PG, Shipley WU. The importance of combined radiation and endocrine therapy in locally advanced prostate cancer. Asian J Androl 2012; 14: 245-6.

9 Xylinas $\mathrm{E}$, Dache $\mathrm{A}$, Roupret $\mathrm{M}$. Is radical prostatectomy a viable therapeutic option in clinically locally advanced $\left(\mathrm{cT}_{3}\right)$ prostate cancer? BJU Int 2010; 106: 1596-600.

$10 \mathrm{NCl}$.Prostate Cancer treatment: stage III prostate cancer. http://www.cancer.gov/ cancertopics/pdq/treatment/prostate/HealthProfessional/page8 (accessed April 2009).

11 Heidenreich A, Aus G, Bolla M, Joniau S, Matveev VB et al. EAU guidelines on prostate cancer. Eur Urol 2008; 53: 68-80.

12 Ward JF, Slezak JM, Blute ML, Bergstralh EJ, Zincke H. Radical prostatectomy for clinically advanced $\left(\mathrm{CT}_{3}\right)$ prostate cancer since the advent of prostate-specific antigen testing: 15-year outcome. BJU Int 2005; 95: 751.

13 Lerner SE, Blute ML, Zincke H. Extended experience with radical prostatectomy for clinical stage $T_{3}$ prostate cancer: outcome and contemporary morbidity. J Urol 1995; 154: $1447-52$

14 Rocco B, Jereczek-Fossa BA, Matei DV, Verweij F, Santoro L et al Intraoperative radiotherapy during radical prostatectomy for intermediate-risk to locally advanced prostate cancer: treatment technique and evaluation of perioperative and functional outcome vsstandard radical prostatectomy, in a matched-pair analysis. BJU Int2009; 104: 1624-30.

15 Charlson ME, Pompei P, Ales KL, MacKenzie CR. A new method of classifying prognostic comorbidity in longitudinal studies: development and validation. J Chron Dis 1987; 40: 373-83.

16 Walsh PC, Donker PJ. Impotence following radical prostatectomy: insight into etiology and prevention. J Urol 1982; 128: 492-7.

17 Dindo D, Demartines N, Clavien PA. Classification of surgical complications-a new proposal with evaluation in a cohort of 6336 patients and results of a survey. Ann Surg 2004; 240: 205-13.

18 Yossepowitch O, Eggener SE, Bianco FJ, Carver BS, Serio A et al. Radical prostatectomy for clinically localized, high risk prostate cancer: critical analysis of risk assessment methods. J Urol 2007; 178: 493-9.

19 Namiki M, Konaka $\mathrm{H}$. What is appropriate neoadjuvant/adjuvant androgen deprivation for high-risk/locally advanced prostate cancer? Asian J Androl 2011; 13: $624-5$.

20 Payne H. Management of locally advanced prostate cancer. Asian J Androl 2009; 11: $81-7$.

21 Payne HA, Gillatt DA. Differences and commonalities in the management of locally advanced prostate cancer: results from a survey of oncologists and urologists in the UK. BJU Int 2007; 99: 545-53.

22 Oh WK, Kantoff PW. Treatment of locally advanced prostate cancer: is chemotherapy the next step? J Clin Oncol 1999; 17: 3664-75. 
23 UICC. TNM Classification of Malignant Tumours. 4th edn, 2nd revision. New York Berlin/Heidelberg: Springer; 1992.

24 Wirth MP, Hakenberg OW, Froehner M. Optimal treatment of locally advanced prostate cancer. World J Urol 2007; 25: 169-76.

25 Widmark A, Klepp O, Solberg A, Damber JE, Angelsen A et al. Endocrine treatment, with or without radiotherapy, in locally advanced prostate cancer (SPCG-7/SFUO-3) an open randomized phase III trial. Lancet 2009; 373: 301-8.

26 Swanson GP. Management of locally advanced prostate cancer: past, present, future. J Urol 2006; 176: 34-41.

27 Freedland SJ, Partin AW, Humphreys EB, Mangold LA, Walsh PC. Radical prostatectomy for clinical stage $\mathrm{T}_{3 \mathrm{a}}$ disease. Cancer 2007; 109: 1273-8.

28 Montie JE. Initial therapy with radical prostatectomy for high-risk localized prostate cancer. J Urol 2006; 176: 27-9.

29 Hisasue S, Takahashi A, Kato R, Shimizu T, Masumori N et al. Early and late complications of radical retropubic prostatectomy: experience in a single institution. Jpn J Clin Oncol 2004; 34: 274-9.

30 Carvalhal GF, Griffin CR, Kan DH, Loeb S, Catalona WJ. Reducing blood loss in open radical retropubic prostatectomy with prophylactic periprostatic sutures. BJU Int 2009; 105: 1650-3.

31 Löppenberg B, Noldus J, Holz A, Palisaar RJ. Reporting complications after open radical retropubic prostatectomy using the Martin Criteria. J Urol 2010; 184: 944-8.
32 Dillioglugil O, Leibman BD, Leibman NS, Kattan MW, Rosas AL et al. Risk factors for complications and morbidity after radical retropubic prostatectomy. J Urol 1997 157: 1760-7.

33 Lepor H, Nieder AM, Ferrandino MN. Intraoperative and postoperative complications of radical retropubic prostatectomy in a consecutive series of 1,000 cases. J Urol 2001; 166: 1729-33.

34 Dafnis G, Wang YH, Borck L. Transsphincteric repair of rectourethral fistulas following laparoscopic radical prostatectomy. Int J Urol 2004; 11: 1047-9.

35 Shekarriz B, Upadhyay J, Wood DP. Intraoperative, perioperative, and long-term complications of radical prostatectomy. Urol Clin N Am 2001; 28: 639-53.

36 Son-Fat H, Hio-Fai L, Kin L, Men-Kin T. Clinical results of radical prostatectomy for patients with prostate cancer in Macau. Chin Med J 2008; 121: 295-8.

37 Loeb S, Smith ND, Roehl KA, Catalona WJ. Intermediate-term potency, continence and survival outcomes of radical prostatectomy for clinically high-risk or locally advanced prostate cancer. Urology 2007; 69: 1170-5.

38 Penson DF, McLerran D, Feng Z, Li L, Albertsen PC et al. 5-year urinary and sexual outcomes after radical prostatectomy: results from the Prostate Cancer Outcomes Study. J Urol 2008; 179: 40-4.

39 Audenet F, Comperat E, Seringe E, Drouin SJ, Richard F et al. Oncologic control obtained after radical prostatectomy in men with a pathological Gleason score $\geqslant 8$ : a single-center experience. Urol Oncol 2011; 29; 602-7. 